\title{
SEMIOTIK TEKS ROLAND BARTHES DALAM KEHIDUPAN \\ KONTEMPORER UMAT BERAGAMA MENGENAI FENOMENA PADU PADAN KEBAYA
}

\author{
Isnaini Rahmawati \\ middleprincess.naysya @gmail.com
}

\begin{abstract}
Abstrak
Tulisan ini mengungkap bagaimana pemikiran semiologi Roland Barthes mengenai sistem tanda dan bagaimana kebaya sebagai image clothing maupun real clothing, dapat berfungsi sebagai tanda (sign) di dalam proses produksi dengan menggunakan teori Roland tersebut serta bagaimana pandangan berbusana kebaya dalam wacana syariah islam di Indonesia. Pemikiran semiologi Roland Barthes meliputi sistem tanda, mitos, dan juga ideologi. Mengenai sistem tanda Barthes menggunakan istilah expression (ekspresi) untuk signifiant $\mathrm{dan}$ content (isi) untuk signifie. Dalam hal ini, teorinya bertumpu pada relasi (R) antara expression (E) dan content (C). Implementasi Semiotika Barthes dalam Fenomena Padu Padan Kebaya. Dalam penerapan semiotika Barthes, makna denotasi dan konotasi tidak dapat dipisahkan, keduanya merupakan perangkat konsep analitis yang perlu dibedakan secara ketat apabila akan dimanfaatkan untuk menganalisis dan memahami busana sebagai fenomena kultural yang bermakna. Penyingkronan dengan kehidupan beragama-pun telah teratasi, terutama dalam agama Islam, telah banyak kebaya yang sengaja dirancang untuk wanita muslimah, dan muslimah sejati bisa memilih dan memilah yang sesuai dengan tuntunan agamanya.
\end{abstract}

Kata kunci: Semiologi, Roland Barthes, Ekspresi, content, kebaya.

\section{PENDAHULUAN}

Kehadiran semiotika memberikan tawaran peluang untuk melihat sesuatu dari berbagai sudut. Dasar pijakan untuk memahami semiotik adalah "tanda". Tanda sebagai suatu hal yang harus dicermati dalam kehidupan. Tanpa melihat adanya 
tanda-tanda, manusia bakal terjerumus dalam hal yang tidak diketahuinya, karena tidak bisa membaca tanda. Oleh karena itu tanda menjadi penting untuk diketahui dalam mengarungi dinamika kehidupan. Tanda memiliki peran penting sebagai alat untuk mempermudah manusia dalam menafsirkan makna.

Kebaya yang dalam perkembangannya telah menjadi trend fashion di Indonesia, dalam hal ini akan dikaji dengan pendekatan semiotik Ronald Barthes. Dalam bukunya Fashion System ia mencoba membedakan beberapa tipe dari busana, yaitu (1) image clothing, busana yang ditampilkan sebagai fotografi atau gambar; (2) written clothing, busana yang dideskripsikan secara tertulis atau ditransformasikan ke dalam bahasa; dan (3) real clothing, busana aktual yang dikenakan pada tubuh manusia, busana sebagai objek (Barthes, 1983: 3 - 5; Barthes 1981: 25 - 27).

Melalui pendekatan semiotik ini, penulis berharap dapat mengungkap bagaimana kebaya sebagai image clothing maupun real clothing, dapat berfungsi sebagai tanda (sign) di dalam proses produksi yang menghasilkan konstruksi makna sebagai perangkat untuk menganalisis suatu kajian busana. Dalam penjelasannya difokuskan pada tataran signifikasi melalui pendekatan semiotik Roland Barthes yang disebutnya dengan denotasi dan konotasi. Selanjutnya secara kontemporer akan diungkap berbagai pandangan berbusana kebaya dalam wacana syariah islam di Indonesia.

\section{TEORI PEMIKIRAN SEMIOLOGI ROLAND BARTHES}

\section{Sistem Tanda}

Dalam teorinya, Roland Barthes masih memperlihatkan dengan jelas teori signifiant-signifie milik de Saussure, namun melalui Hjemslev, Barthes menggunakan istilah expression (ekspresi) untuk signifiant dan content (is i) untuk signifie. ${ }^{1}$ Dalam hal ini, teorinya bertumpu pada relasi (R)

\footnotetext{
${ }^{1}$ Benny H. Hoed, "Strukturalisme de Saussure di Prancis dan Perkembangannya," dalam Prancis dan Kita, (Jakarta: Wedatama Widya Sastra, 2003), hlm. 19
} 
antaraexpression (E) dan content (C), sehingga ia mengemukakan model E-R-C. Sebuah sistem tanda primer bisa menjadi sebuah elemen dari sistem tanda yang lebih luas. ${ }^{2}$

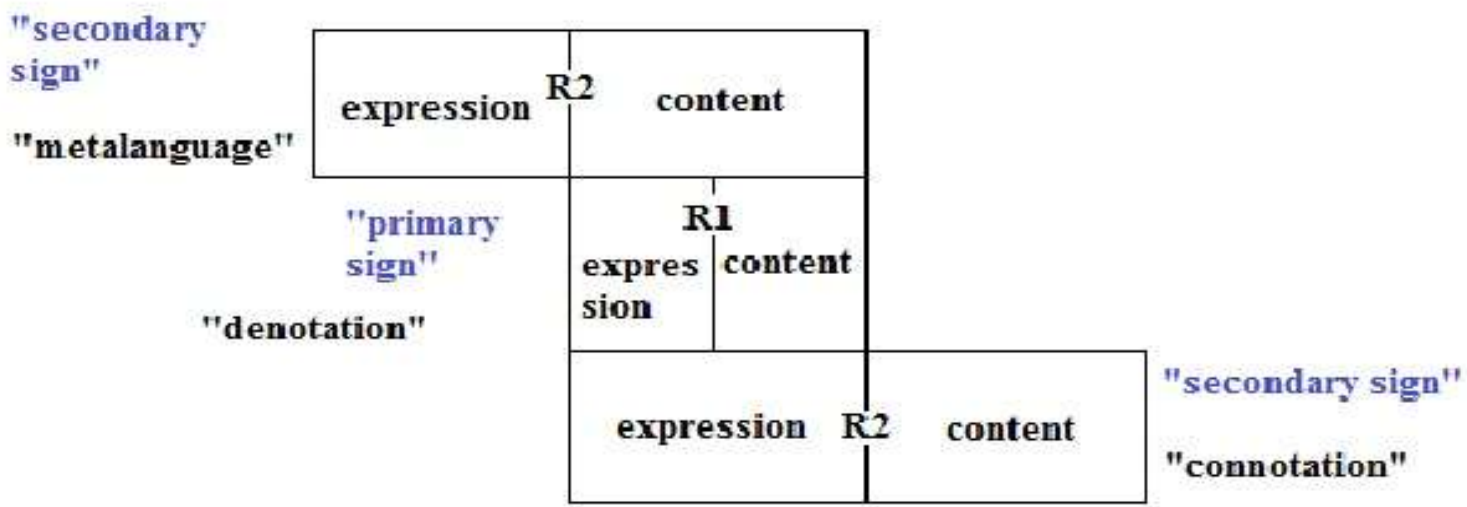

Dalam kasus ini tanda primer adalah semiotik konotatif. Kelanjutan sistem tanda tingkat pertama juga muncul bersama tambahan ekspresi baru. Inilah tanda-tanda dalam kasus metalinguistik dimana sistem primer adalah denotasi dan sistem sekunder terdiri dari metabahasa (metalanguage). Pada sistem tanda tingkat kedua, konotasi mengambil tanda primer sebagai ekspresinya, metabahasa mengambil itu sebagai isinya (content).

\section{Mitos}

Menurut Barthes dalam bukunya yang berjudul Mythologies, mitos adalah sebuah sistem komunikasi, bahwa mitos adalah sebuah pesan. Mitos adalah mode penandaan, sebuah wujud. Barthes percaya bahwa semua benda bisa menjadi mitos. Asalkan bendatersebut sudah mengandung pesan, maka benda itu menjadi mitos. Menurut Barthes sifat lain dari mitos adalah bahwa mitos tidak ditentukan oleh materinya, melainkan oleh

\footnotetext{
${ }^{2}$ W. Noth, The Handbook of Semiotics, (St Paul/Indianapolis: Indiana University Press, 1995), hlm. 310
} 
pesan yang disampaikan. ${ }^{3}$ Mitos tidak selalu bersifat verbal, sehingga juga ada mitos dalam bentuk film, lukisan, patung, fotografi, iklan, atau komik.

Mitologi adalah bagian dari semiologi, yaitu ilmu yang luas tentang tanda dan bentuk. Mitologi dan semiologi, kedua-duanya berurusan dengan nilai yang tidak hanya puas dengan fakta. ${ }^{4}$ Fakta merupakan tanda yang digunakan untuk mendefinisikan dan menjelajahi hal lainnya. Menurut Barthes ${ }^{5}$, dalam mitos ditemukan pola tiga dimensi penanda, petanda, dan tanda. Tapi mitos adalah sebuah sistem khusus yang dibangun dari rantai semiologis yang sudah ada sebelumnya.

\section{Bahasa/Denotasi}

\section{MITOS/Konotasi}

\begin{tabular}{|c|c|c|}
\hline 1. Penanda & 2. Petanda & \\
\hline \multicolumn{2}{|c|}{ 3. Tanda } & \\
\hline \multicolumn{2}{|c|}{ I PENANDA } & II PETANDA \\
\hline \multicolumn{3}{|c|}{ III TANDA } \\
\hline
\end{tabular}

Proses signifikasi ini disebutnya denotasi dan konotasi. ${ }^{6}$ Makna denotasi bersifat langsung, artinya makna khusus yang terdapat dalam suatu tanda atau gambaran dari sebuah petanda. Sedang makna konotasi akan dihubungkan dengan kebudayaan yang tersirat dalam pembungkusnya, yaitu makna yang terkandung di dalamnya. $^{7}$

${ }^{3}$ Okke Zaimar, Semiotik dan Penerapannya dalam Karya Sastra, (Jakarta: Pusat Bahasa, 2008), hlm. 58

${ }^{4}$ Roland Barthes, Mythologies, (New York: The Noonday Press, 1972), hlm. 107

${ }^{5}$ Ibid., hlm. 113

${ }^{6}$ Kris Budiman, Jejaring Tanda-tanda : Strukturalisme dan Semiotika dalam Kritik Kebudayaan, (Magelang: Indonesiatera, 2004), hlm. 63-65

${ }^{7}$ Arthur Asa Berger, Tanda-tanda dalam Kebudayaan Komtemporer: Suatu Pengantar Semiotika, 


\section{Ideologi}

Masyarakat kita adalah lahan istimewa penandaan mistis karena secara formal, mitos adalah instrumen yang paling tepat bagi pembalikan ideologis yang mendefinisikan masyarakat. ${ }^{8}$ Dengan memahami mitos dalam suatu masyarakat, maka kita dapat memahami budayanya. Lebih jauh lagi, mitologi mengubah nilai-nilai suatu budaya, dalam kasus Barthes adalah budaya borjuis Prancis, menjadi nilai yang universal dan alami. ${ }^{9}$

Mitologi mengubah budaya menjadi alam. Mitos sebagai produk budaya. Barthes memberikan contoh dari sampul majalah Paris-Match. Foto sampulnya menunjukkan seorang pria muda berkulit hitam sedang memberi hormat militer. Mata pria muda itu diangkat ke atas, mungkin sedang menatap bendera Prancis. Kenyataannya memang ada pria berkulit hitam yang difoto dalam fose menggunakan pakaian itu. Tetapi ada makna lain, yaitu bahwa Prancis adalah Kerajaan yang besar, bahwa semua warganya, tanpa diskriminasi warna kulit, dengan setia melayani di bawah benderanya. Pengertian ideologis seperti ini terhadap teks kebudayaan tidak terhindarkan. Apa yang dimaksud dengan ideologi adalah proses di mana apa yang bersifat historis dan diciptakan oleh budaya-budaya tertentu dihadirkan seakan-akan tanpa masa, universal, dan alami. ${ }^{10}$

\section{PEMIKIRAN ROLAND BARTHES DALAM KARYA-KARYANYA}

\section{Mythologies}

Buku Barthes yang berjudul Mythologies terdiri atas dua subbab, yakni: (1) "Mythologies", dan (2) "Myth Today". Jangan berharap kalau dalam buku ini Barthes membicarakan dan mengulas tokoh-tokoh mitologi Yunani atau Romawi seperti Zeus dan dewa-dewa Olympus lainnya, Hercules dan hero-hero lainnya,

(Yogyakarta: Tiara Wacana, 2005), hlm. 55

${ }^{8}$ Roland Barthes, Mythologies, (New York: The Noonday Press, 1972), hlm. 142

${ }^{9}$ Graham Allen, Roland Barthes, (New York: Routledge, 2003), hlm. 37

${ }^{10}$ Ibid., hlm. 35 
ataupun rentetan Perang Troya sebagaimana dikisahkan dalam Iliad dan Odiseus yang sangat dikenal tidak hanya oleh masyarakat Eropa tetapi juga di belahan bumi lainnya termasuk di Indonesia. Barthes sama sekali tidak menyinggung peristiwa maupun tokoh mistis dan legendaris tersebut.

Pada bagian pertama buku Mythologies, Barthes mengungkapkan topik-topik kontemporer semacam dunia gulat, romantisme dalam film, anggur dan susu, irisan steak, wajah Garbo, otak Einstein, manusia Jet, masakan ornamental, novel dan anak-anak, mainan (toys), mobil Citroën, plastik, fotografi, tarian striptease, dan topik-topik pop lainnya. Sebagaimana dinyatakan dalam pengantarnya pada cetakan pertama (1957), Barthes menyatakan bahwa tulisan-tulisannya dalam buku ini merupakan sejumlah esai tentang topik-topik masa itu yang dia tulis setiap bulan untuk sejumlah media massa.

Topik-topik yang menarik perhatiannya ini, tidak lain merupakan refleksi atas mitos-mitos baru masyarakat Prancis kontemporer. Lewat berbagai analisisnya tentang peristiwa-peristiwa yang ditemuinya dalam artikel surat kabar, fotografi dalam majalah mingguan, film, pertunjukan, ataupun pameran, Barthes mengungkapkan sejumlah mitos-mitos modern yang tersembunyi di balik semua hal itu. Mitos inilah yang oleh Barthes disebut sebagai second order semiotic system, yang harus diungkap signifikansinya. Mitos merupakan salah satu type of speech. Jabarannya mengenai konsep mitos-mitos masa kini sebagai kajian sistem tanda dibicarakan pada subbab yang kedua yang berjudul "Myth Today".

\section{The Fashion System}

Dalam buku The Fashion System, Barthes membicarakan panjang lebar mengenai dunia mode. Sebagaimana bukunya yang terdahulu, dalam buku ini Barthes juga membicarakan operasi struktur penanda (signifier) mode, struktur petanda (signified)-nya, dan struktur sign atau signifikansinya. Memang kajian mode atau 
fashion Barthes tidak terlepas dari bidang semiotika yang selama ini dikembangkannya.

Dunia mode merupakan proyek model kaum aristokrat sebagai salah satu bentuk atau wujud pretise. Pada perkembangan berikutnya, model pakaian seseorang juga harus disesuaikan dengan fungsinya sebagai tanda, yang membedakan antara pakaian untuk kantoran, olah raga, liburan, berburu, upacara-upacara tertentu, bahkan untuk musim-musim tertentu. Manusia pengguna pakaian yang mengikuti trend akan mengejar apa yang tengah menjadi simbol status kelas menengah atas. Yang tidak mengikuti arus dunia mode akan dikatakan manusia yang tidak fashionable alias ketinggalan mode. ${ }^{11}$

Tata busana tidak lagi menjadi sekedar pakaian tetapi juga telah menjadi mode, menjadi peragaan busana, menjadi simbol status kehidupan. Hal ini tidak hanya terjadi di dunia Barat saja, tetapi juga tengah melanda Indonesia. Barthes tidak salah membidik salah satu aspek ini, yakni mode, sebagai salah satu kajiannya, mengingat Paris merupakan kiblat mode dunia. Begitulah, salah satu topik pembicaraan Barthes tentang aspek kebudayaan massa yakni tentang dunia mode. Dunia yang kini penuh dengan kemewahan para model yang memperagakannya di sejumlah catwalk pusat-pusat peragaan busana di berbagai kota metropolis. Status seseorang dalam masyarakat seringkali dicitrakan melalui merk dan rancangan siapa pakaian yang dikenakannya.

\section{The Photographic Message}

Selain bicara tentang mode, Barthes juga berbicara tentang foto, khususnya tentang foto-foto dalam media massa dan iklan. Hal ini diungkapkannya dalam dua artikelnya, "The Photographic Message" pada 1961 dan "Rethoric of the Image" juga pada 1961. Lewat dua artikelnya ini, Barthes menguraikan makna-makna

${ }^{11}$ http://banggaberbahasa.blogspot.com/2012/09/semiotika-menurut-pandangan-rola nd_820.html diakses hari Sabtu, 18 April 2014 pukul 13:23 WIB. 
konotatif yang terdapat dalam sejumlah foto dalam media massa dan iklan. Foto sebagai salah satu sarana yang sanggup menghadirkan pesan secara langsung (sebagai analogon atau denotasi) dapat meyakinkan seseorang (pembaca berita atau iklan) bahwa peristiwa tersebut sudah dilihat oleh seseorang, yakni fotografer. Akan tetapi, di balik peristiwa tersebut, ternyata foto juga mengandung pesan simbolik (coded-iconic message) yang menuntut pembacanya untuk menghubungkannya dengan "pengetahuan" yang telah dimiliki sebelumnya.

Dalam beberapa media massa di Indonesia pada tahun 1998, ketika Presiden Soeharto menandatangani LoI dengan IMF, tampak Camdesus tengah memperhatikan Soeharto yang tengah membubuhkan tanda tangan. Wakil IMF itu berdiri mengawasi dengan posisi tangan bersedekap. Sebagai analogon atau makna denotasi, foto ini hanya menyatakan telah terjadi penandatangan nota persetujuan antara RI yang diwakili Soeharto dengan IMF yang diwakili Camdesus. Akan tetapi, posisi tangan Camdesus dan caranya memandang Soeharto membubuhkan tanda tangan secara konotatif memaknakan dia telah menaklukkan seorang pemimpin yang telah 32 tahun berkuasa.

Contoh-contoh analisis semacam inilah yang dikemukakan Barthes dalam analisisnya tentang sejumlah foto. Salah satunya tentang seorang tentara berkulit hitam yang mengenakan seragam militer Prancis yang tengah memberikan penghormatan militer, matanya terpancang pada bendera nasional. Foto ini menjadi sampul dari majalah Paris-Match. Dalam analisisnya, Barthes menyatakan bahwa foto itu ingin menyatakan Prancis sebagai sebuah negara besar, tempat para putranya, tanpa diskriminasi warna kulit, dengan penuh setia, melayani bangsa di bawah kibaran benderanya. Foto itu merupakan konter atas para pencela kolonialisme. ${ }^{12}$

\footnotetext{
${ }^{12}$ Jonathan Culler. Barthes, Seri Pengantar Singkat (terjemahan Ruslani), (Yogyakarta: Jendela, 2002), hlm. 52.
} 


\section{PENERAPAN SEMIOTIKA ROLAND BARTHES DALAM FENOMENA PADU PADAN KEBAYA DAN PENYESUAIANNYA DALAM KEHIDUPAN KONTEMPORER BERAGAMA}

Roland Barthes mengemukakan gagasan yang dikenal sebagai "order of signification", yang terdiri dari makna denotasi (makna sesungguhnya yang sesuai dengan kamus dan realitas), serta makna konotasi (makna ganda yang muncul dari pengalaman secara personal dan kultural). Inilah yang membedakan teori Barthes dengan Saussure, dimana Barthes ingin menunjukkan bahwa adanya interaksi antara teks dengan pengalaman personal dan cultural penggunanya, interaksi antara konvensi dalam teks dengan konvensi yang dialami dan diharapkan oleh penggunanya. Teori ini berdasar pada kenyataan bahwa kalimat yang sama bisa saja dimaknai secara berbeda oleh orang yang berbeda situasi dan kondisinya. ${ }^{13}$

Sebagai umpan penerapan teori semiotika ini, penulis akan mengaplikasinya ke dalam "kebaya padan polkadot" dengan "kebaya padan selendang panjang".

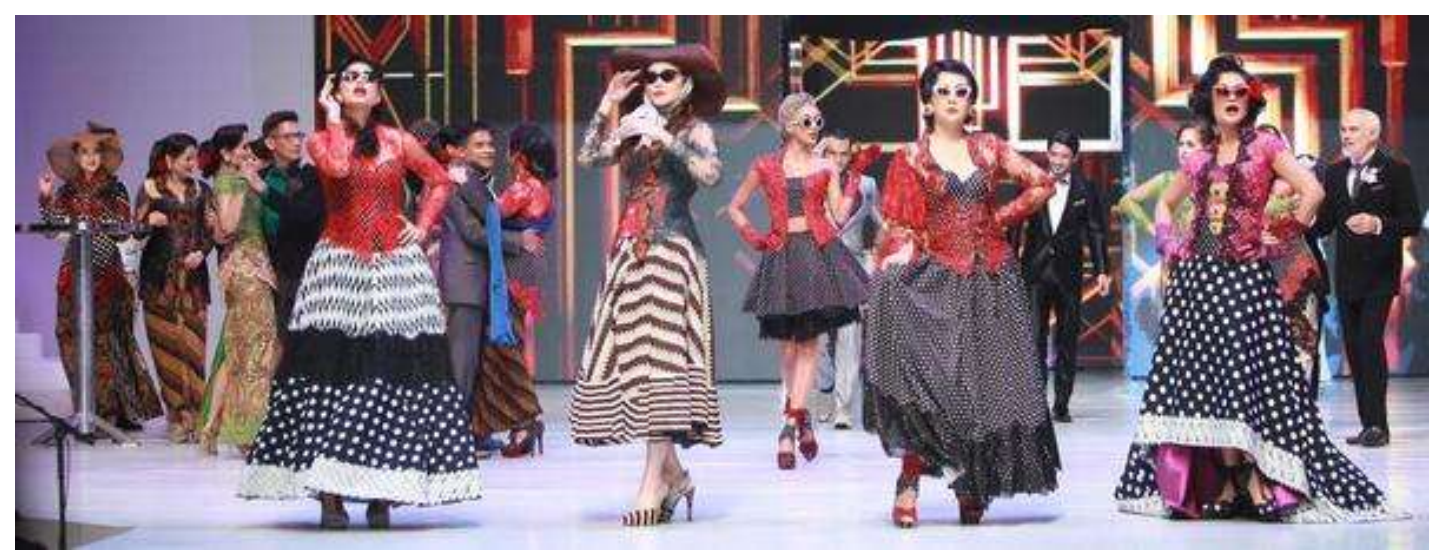

Aneka motif polkadot bersanding serasi dengan siluet kebaya model encim berpalet merah.

(foto: NOVA / Agus Dwianto)

Pada tataran pertama, aneka garis, bentuk, warna, tekstur dan lain-lain disusun untuk menyajikan sebuah kebaya dengan padanan aneka motif polkadot.

\footnotetext{
${ }^{13}$ Muhammad Taufik Ishak, Pembacaan Kode Semiotika Roland Barthes terhadap Bangunan Arsitektur Katedral Evry di Perancis Karya Mario Botta. RONA Jurnal Arsitektur FT-Unhas , 2, 2005), hlm. 85-92.
} 
Suasana retro klasik pada tahun 1950-an, pencampuran bahan brokat dengan bahan bermotif, serta aksesori kacamata model cat eye dan sarung tangan bahan velvet. Proses pemaknaan pada tataran ini menghasilkan denotasi signifikasi tataran pertama (first order signification). Makna denotasi ini merupakan makna harafiah dari suatu obyek atau citra, yakni apa yang tergambarkan pada obyek atau citra tersebut.

Pada tataran kedua (second order signification), mengaitkan tanda tersebut (kebaya padan polkadot) dengan suatu konsep, makna, atau tema kultural tertentu yang lebih luas, misalnya kebarat-baratan, jauh dari budaya Indonesia, terkontaminasi dengan budaya lain. Pada makna konotasi dapat menafsirkan makna, mengasosiasikan makna yang berbeda-beda pada setiap orang untuk objek yang sama, dikarenakan perbedaan etnik, usia, klas sosial, dan sebagainya.

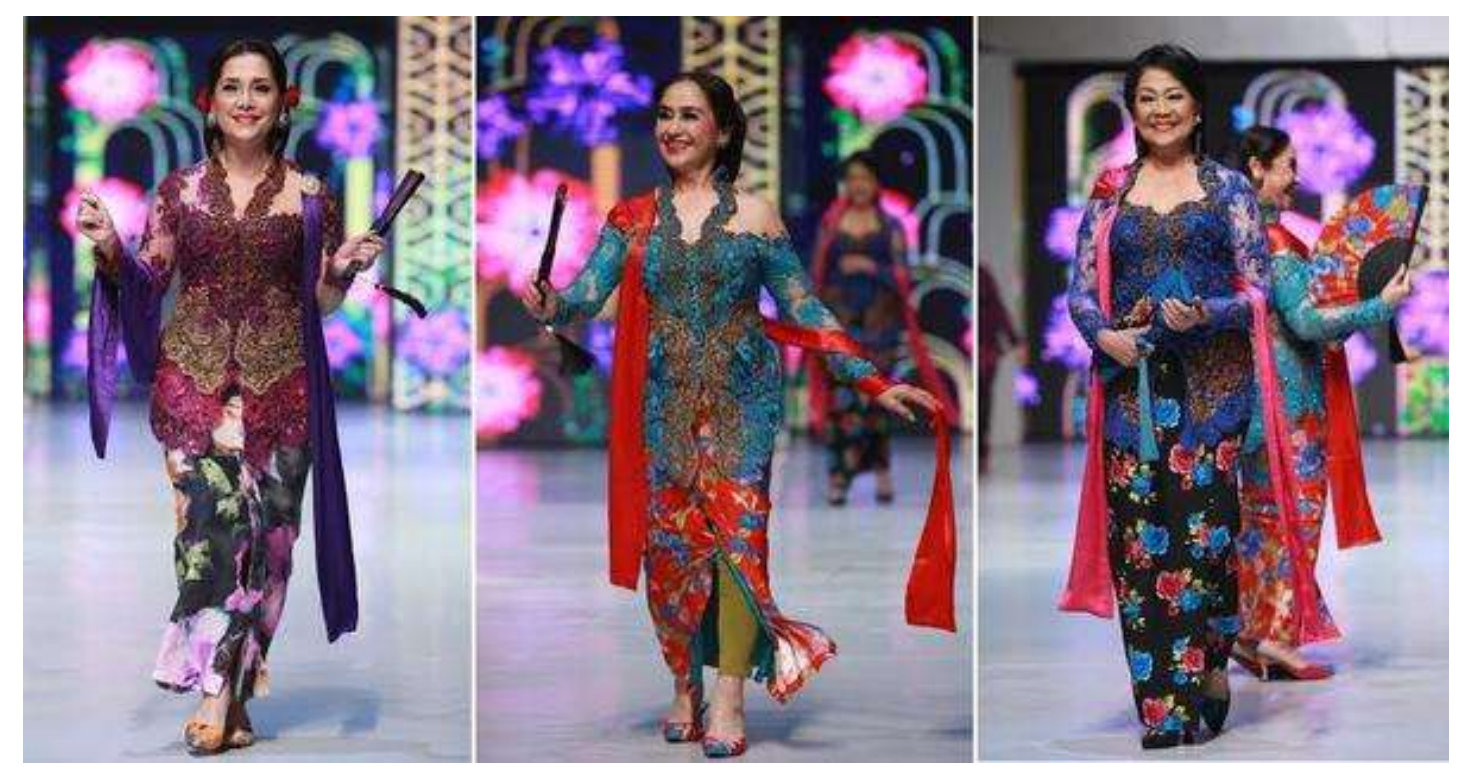

Kebaya santun lengkap dengan selendang panjang melingkar di bagian bahu berwarna kontras.

(foto: NOVA / Agus Dwianto)

Penanda-penanda yang dapat diidentifikasi antara lain kembali pada pakem kebaya modern kontemporer, yang menampilkan kebaya santun lengkap dengan selendang panjang melingkar di bagian bahu berwarna kontras seperti pink. Brokat berdetail manik bebatuan dan payet berwarna hijau emerald, biru safir, merah cabai 
berpadu kain sutra bermotif penuh. Penanda-penanda ini, pada semiologis tingkat pertama (denotasi), disebut kebaya santun dengan selendang panjang.

Kemudian pada tataran kedua (konotasi) seluruh perangkat penanda tadi beserta petandanya akan beralih posisi, sebagai petanda makna baru yaitu "penampilan anggun", "sopan”, dan "elegant” sesuai dengan budaya Indonesia yang ramah-tamah.

Penyesuaian dalam kehidupan kontemporer beragama. Sebagai bahan sandang, kebaya memiliki nilai sejarah yang cukup panjang. Seperti diketahui bahwa pengetahuan nenek moyang kita terhadap sandang telah mencapai kesempurnaan sejak berdirinya kerajaan-kerajaan. Kesempurnaan itu semakin diperkokoh lagi atau semakin bervariasi sejak kedatangan kebudayaan Hindu. Hal itu sangat dimungkinkan karena dalam kebudayaan Hindu dengan segala aspek aktivitas religinya membutuhkan kehadiran busana yang berbeda-beda seperti busana ke sawah, busana untuk bergotong royong membangun rumah, maupun busana untuk bermain musik, seperti yang terlihat di relief candi Borobudur. Pengetahuan terhadap sandang itu semakin lebih bermakna secara etis lewat persentuhan budaya Islam yang lebih banyak menekankan pada bagaimana berbusana menurut kaidah agama. ${ }^{14}$

Masalah busana wanita Indonesia harus didudukkan dalam paradigma umumnya, artinya bahwa sebagai kaum muslimah Indonesia harus mempertahankan dan tetap komitmen dengan busananya yang dibenarkan syariat Islam dan tidak boleh tunduk kepada dogma tradisi pra Islam di nusantara, doktrin serta paradigma sekuler yang menentukan bahwa yang diakui sebagai 'Busana Wanita Indonesia' secara resmi adalah setelan kebaya lengkap dengan kondenya. Bila demikian maka hukumnya memakai tersebut adalah haram. Hal itu dapat kita pahami dari ketentuan syariat Islam bagi busana wanita di luar rumah dan busana pergaulan yaitu bahwa mode, corak dan bentuknya dapat bersifat dinamis, kreatif dan trendi selama memiliki

\footnotetext{
${ }^{14}$ Henk Schulte Nordholt, Outward Appearances, (Yogyakarta: LKIS, 2005).
} 
kriteria umum sebagai berikut: ${ }^{15}$

- Menutup seluruh tubuh kecuali muka dan telapak tangan, sebagaimana difatwakan Ibnu Abbas ketika menafsirkan surat An-Nur:31, demikian pula Ibnu Umar, Anas, Aisyah, dan Ibnu Hazm (Asy-Syaukani, Nailul Authar, 2/68)

- Tidak tipis, transparan dan menampakkan bentuk badan dan menggambarkan lekuk-lekuk tubuh. "Dua golongan termasuk penghuni neraka yang belum pernah kulihat seperti mereka; yaitu sekumpulan orang yang selalu memegang cemeti seperti ekor sapi yang suka memukul orang, dan para wanita yang berpakaian tapi telanjang, membuka kain penutup dan berjalan melenggok-lenggok,...” (HR. Muslim) Maksud "berpakaian tapi telanjang” (kasiyat 'ariyat) yaitu pakaian yang tidak berfungsi menutup aurat, sehingga sangat jelas menggambarkan bentuk tubuh dan kulit karena tipis atau ketatnya.

- Tidak menyerupai pakaian khusus laki-laki (HR. Ahmad). Rasulullah melaknat laki-laki yang meniru penampilan wanita dan wanita yang meniru penampilan laki-laki (HR. Bukhari)

- Tidak meniru dan menyerupai busana khas wanita-wanita musyrik dan kafir. (HR. Muslim) Sabda Nabi saw. : "Barang siapa yang menyerupai suatu kaum, maka ia termasuk golongan mereka.” (HR.Muslim).

Ciri dan ketentuan syariat di atas menjadi tanda maupun lambang tersendiri bagi muslimah sejati. Bukankah Allah itu Maha Indah dan mencintai keindahan. (HR.Muslim) Bahkan Allah sendiri menganjurkan kepada keindahan hakiki yaitu yang mengkombinasikan keindahan lahiriah (estetika) dengan keindahan batin yang memancar kepada akhlak (etika). (QS. al-A'raf: 31-32).

\section{KESIMPULAN}

Pertama; Pemikiran semiologi Roland Barthes meliputi sistem tanda, mitos, dan juga ideologi. Mengenai sistem tanda Barthes menggunakan istilah expression

\footnotetext{
${ }^{15}$ http://ustadzsbu.blogspot.com/2009/04/hari-kartini-antara-mitos-distorsi-dan_12.html diakses hari Sabtu, 18 April 2015 pukul 23.30 WIB
} 
(ekspresi) untuk signifiant dan content (isi) untuk signifie. Dalam hal ini, teorinya bertumpu pada relasi $(R)$ antaraexpression (E) dan content (C). Mitos menurut Barthes adalah sebuah sistem komunikasi, bahwa mitos adalah sebuah pesan. Dalam mitos ditemukan pola tiga dimensi penanda, petanda, dan tanda. Kemudian ideologi, mitos adalah instrumen yang paling tepat bagi pembalikan ideologis. Dengan memahami mitos dalam suatu masyarakat, maka kita dapat memahami ideologinya.

Kedua; Menengok pemikiran Roland Barthes melalui karyanya seperti dalam buku Mythologies, Barthes mengungkapkan sejumlah mitos-mitos modern yang tersembunyi di balik semua hal. Mitos inilah yang oleh Barthes disebut sebagai second order semiotic system, yang harus diungkap signifikansinya. Dalam buku The Fashion System, kajian mode atau fashion Barthes tidak terlepas dari bidang semiotika, mode berpakaian seseorang juga harus disesuaikan dengan fungsinya sebagai tanda dan Camera, foto juga mengandung pesan simbolik (coded-iconic message) yang menuntut pembacanya untuk menghubungkannya dengan "pengetahuan” yang telah dimiliki sebelumnya.

Ketiga; Implementasi Semiotika Barthes dalam Fenomena Padu Padan Kebaya. Dalam penerapan semiotika Barthes, makna denotasi dan konotasi tidak dapat dipisahkan, keduanya merupakan perangkat konsep analitis yang perlu dibedakan secara ketat apabila akan dimanfaatkan untuk menganalisis dan memahami busana sebagai fenomena kultural yang bermakna. Penyingkronan dengan kehidupan beragama-pun telah teratasi, terutama dalam agama Islam, telah banyak kebaya yang sengaja dirancang untuk wanita muslimah, dan muslimah sejati bisa memilih dan memilah yang sesuai dengan tuntunan agamanya. 


\section{DAFTAR PUSTAKA}

Allen, Graham. 2003. Roland Barthes. New York: Routledge.

Barthes, Roland. 1972. Mythologies. New York: The Noonday Press

Culler, Jonathan. 2002. Barthes, Seri Pengantar Singkat (terjemahan Ruslani). Yogyakarta: Jendela.

Berger, Arthur Asa. 2005. Tanda-tanda dalam Kebudayaan Komtemporer: Suatu Pengantar Semiotika, Yogyakarta: Tiara Wacana.

Budiman, Kris. 2004. Jejaring Tanda-tanda: Strukturalisme dan Semiotika dalam

Kritik Kebudayaan, Magelang: Indonesiatera.

Hoed, Benny H. 2003. "Strukturalisme de Saussure di Prancis dan Perkembangannya," dalam Prancis dan Kita, Irzanti Sutanto dan Ari Anggari Harapan (peny.). Jakarta: Wedatama Widya Sastra.

Nordholt, Henk Schulte. 2005. Outward Appearances, Yogyakarta: LKIS.

Noth, W. 1995. The Handbook of Semiotics. St Paul/Indianapolis: Indiana University Press.

Zaimar, Okke K.S. 2008. Semiotik dan Penerapannya dalam Karya Sastra. Jakarta: PusatBahasa. 